\title{
A ideia de Deus em Hegel ${ }^{1}$
}

\author{
The concept of God in Hegel
}

\section{Markus Gabriel}

Professor titular da cátedra de Epistemologia, Filosofia Moderna e Contemporânea da Universidade de Bonn, Bonn Alemanha, e-mail: gabrielm@uni-bonn.de

\section{Resumo}

Li em um ensaio a declaração de Hegel de que "Deus está morto", como a reivindicação de que Deus como espírito absoluto é o horizonte fundamental da compreensão própria de uma determinada comunidade. Nem "Deus" nem "espírito" em Hegel se referem a uma entidade transcendente ou garantia teleológica de sentido, mas apenas à prática comunitária de fazer sentido. No caso do espírito absoluto, a comunidade faz sentido de suas práticas de fazer sentido. Na religião, essa autorreferência é apresentada como algo divino. Hegel lê essa divindade como um restante de metafísica problemática a ser superada em seu conceito de Deus.

Palavras-chave: Hegel. Espírito absoluto. Ontoteologia. Deus. Morte de Deus.

1 Agradeço a Carlos João Correia pela sua ótima tradução dos textos de Hegel e por ter corrigido o meu português. 


\section{Abstract}

In the paper, I read Hegel's declaration that "God is dead" as the claim that God as absolute spirit is the ultimate horizon of a particular community's self-understanding. Neither "God" nor "spirit" in Hegel refer to a transcendent entity or teleological guarantee of sense, but only to the communitarian practice of sense making. In the case of absolute spirit, the community makes sense of its practices of sense making. In religion, this self-reference is presented as something divine. Hegel reads this divinity as a remainder of problematic metaphysics to be sublated in his concept of God.

Keywords: Hegel. Absolute spirit. Ontotheology. God. Death of God.

A filosofia de Hegel deixa-se descrever como monismo absoluto. Nesse sentido, Hegel é herdeiro de Espinosa: não há nada que possa transcender a totalidade das manifestações da unidade entre sujeito (substantia cogitans) e objeto (substantia extensa). Na esteira de Espinosa, Hegel critica todas as metafísicas da transcendência que pressupõem a possibilidade de um absoluto fora ou antes da reflexão. Contudo, Hegel reconhece a necessidade da religião apesar de ela fundar-se no conceito de um Deus que não é deste mundo. Tal autor insiste que a religião tende a exprimir um conceito imanente, i. e., o próprio conteúdo do pensamento metafísico. Segundo ele, a história da religião desemboca na chamada "religião absoluta", que se transforma em um monismo do espírito na esteira do idealismo alemão.

Hegel discerne, assim, dois momentos principais da religião absoluta: a morte de Deus e a trindade. Para esse autor, tal como para Nietzsche, a morte de Deus (i.e., a morte de Cristo) significa a morte da transcendência, ideia essa que também subjaz à declaração nietzschiana da morte de Deus (HEIDEGGER, 2003; HOULGATE, 1986). Hegel afirma que a época moderna se define pela perda do mundo transcendente. A época moderna é, por conseguinte, a época do monismo. Na primeira parte deste ensaio, esboçarei essa ideia de Deus enquanto ideia da morte de Deus. 
A imanência de Deus mostra-se como manifestação pura, i. e., como manifestação reflexiva que apenas expressa a atividade de revelar a totalidade dos conteúdos ao pensamento. Ao contrário da interpretação estandardizada, tentarei demonstrar que Hegel não transcende os limites da finitude, mas, sim, que corrobora esses limites ao conceber Deus como o espírito da comunidade. Deus não existe fora desse espírito, o que, entretanto, não implica que não existe. Deus não significa a dimensão da comunidade na qual se realiza o processo de uma revelação absoluta, revelação essa que mostra que o ser resulta da atividade do pensamento. Essa atividade manifesta-se na linguagem da comunidade. Na segunda parte deste ensaio, reconstruirei esta afirmação da finitude na filosofia da religião de Hegel. A finitude do espírito absoluto consiste no fato da sua expressão, i. e., da sua manifestação se realizar no meio envolvente da linguagem da comunidade. Por isso, Hegel não reclama uma "intuição intelectual" do absoluto sob o nome do "espírito absoluto", mas tenta explicar, na maneira bem conhecida da Fenomenologia do espírito, a totalidade das definições fracassadas do absoluto pela consciência. Assim, a consciência não realiza a não existência de uma substância transcendente (do "em si"), ela não se apercebe do seu papel na constituição do absoluto "para si". Não há, pois, nada em si que não seja em si para nós. Para Hegel, todas as variações do tema "em si" de Platão a Kant, i. e., todas as "definições do absoluto" falham precisamente por serem definições de um processo de pensamento no qual revelam a manifestação da manifestação. ${ }^{2}$

\section{Deus está morto}

A maior diferença entre Hegel e Espinosa encontra-se no próprio conceito de Deus enquanto princípio e fundamento de todos os seres limitados. Enquanto Espinosa concebe Deus como substância, ou seja, como a unidade real dos atributos da extensão e do pensamento,

2 Desenvolvo os pormenores dessa interpretação no meu artigo Die metaphysische Wahrheit des Skeptizismus bei Schelling und Hegel. Internationales Jahrbuch des Deutsche Idealismus, v. 5, p. 126-156, 2007. 
Hegel chama a nossa atenção para o fato de que todas as unidades metafísicas só podem ser pressuposições do nosso pensamento metafísico. ${ }^{3}$ Com efeito, não há uma unidade substancial atrás dos fenômenos deste mundo, mas apenas uma série de sistemas metafísicos que definem o absoluto de maneiras diferentes. Nesse sentido, o programa de Hegel é o de deduzir a totalidade das pressuposições metafísicas em vez de descobrir uma unidade substancial, um absoluto determinado. Como Heidegger fará mais tarde, Hegel reconstrói uma história do pensamento do absoluto (do Ser) em vez de confinar o absoluto a uma das suas manifestações. Por isso, Hegel tenta substituir o conceito da substância pela ideia do sujeito. ${ }^{4}$

No primeiro livro da Ética, Espinosa diz-nos que Deus, i.e., substantia una, não tem limites. Segundo Espinosa, Deus é, então, infinito. De acordo com os seus pressupostos conceituais, isso quer dizer que a substância exclui todas as negações, nullam negationem involvit. ${ }^{5}$ Logo, a substância absoluta é uma positividade pura para além de todas as negações. Contudo, Hegel critica essa afirmação porque ela não explica como uma positividade pura pode ser determinada como tal sem implicar negações. Segundo Hegel, a negação de todas as negações, i. e., o próprio conceito da substância, já implica uma negação de segunda ordem e é, portanto, incoerente. Uma positividade pura, a qual Hegel designa por "Ser" no início da Ciência da lógica, é inconcebível e, por isso, idêntica ao nada.

$\mathrm{O}$ absoluto tem, assim, que englobar a negação em si mesmo por não ser nada. Se o absoluto fosse uma substância no sentido espinosano, nem sequer seria o absoluto. Por isso, o absoluto precisa da negação, ou seja, da atitude metafísica para se tornar Deus, estrutura essa a que Hegel chama de "sujeito" ou de "personalidade

3 Por essa razão Hegel rejeita todas as formas da metafísica transcendente. Veja-se GABRIEL, M. Hegel und Plotin. In: HEIDEMANN, D.; KRIJNEN, C. (Ed.). Hegel und die Geschichte der Philosophie. Darmstadt: Wissenschaftliche Buchgesellschaft, 2007; GABRIEL, M. The Dialectic of the Absolute: Hegel's critique of transcendent metaphysics. In: LIMNATIS, N. (Ed.). The dimensions of Hegel's dialectic. Chicago, 2009. No prelo.

4 "Es kommt meiner Einsicht, welche sich nur durch die Darstellung des Systems selbst rechtfertingen muß, alles darauf an, das Wahre nicht als Substanz, sondern ebensosehr als Subjekt aufzufassen und auszudrücken" (TWA, 3, 22).

5 Espinosa, Ética: Eld6exp.

Rev. Filos., Aurora, Curitiba, v. 23, n. 33, p. 525-537, jul./dez. 2011 
pura" (TWA, 6, 569). ${ }^{6}$ A subjetividade do absoluto consiste no fato de o absoluto ser pensado pelo pensamento finito. Segundo Hegel, essa estrutura encontra-se no seio da religião cristã, nomeadamente no dogma da ressurreição.

Deus morreu, Deus está morto - este é o mais terrível pensamento de que tudo o que é eterno e verdadeiro não existe, estando a própria negação em Deus; a mais elevada dor o sentimento de perdição completa, a anulação do mais elevado está-lhe por isso associado - o processo não pára no entanto aqui, mas reaparece na reversão; nomeadamente Deus narra-se neste processo e este é apenas a morte da morte. Deus retornou à vida; este processo tornou-se, assim, no seu oposto (TWA, $17,290-291)^{7}$

A ressurreição pressupõe a morte de Deus. Como Hegel sublinha em vários passos da sua obra, essa morte manifesta-se na época moderna por meio do niilismo. A subjetividade moderna emancipa-se da ideia de um Deus transcendente, substituindo-a pela ideia de comunidade. Aliás, a ausência de Deus, a morte de Deus, exige uma reconciliação. A época moderna enquanto "disjunção (Entzweiung)" (TWA, $2,19)$ de sujeito e objeto apela a uma unidade à qual Hegel chama de "reversão (Umkehrung)". Essa reversão tem lugar na reflexão que desvela as representações religiosas para descobrir o seu coração racional, i. e., metafísico da religião.

Para Hegel, a época moderna caracteriza-se, entre outras coisas, por uma lacuna entre razão e religião, pela qual Hegel desenvolve um novo conceito de religião. Religião e filosofia têm o mesmo conteúdo, i. e., o espírito absoluto, mas distinguem-se pela forma de imagens, expressão. Enquanto a religião representa o conteúdo absoluto na forma de imagens, de metáforas, alegorias e parábolas, a filosofia reflete sobre

6 Cita-se Hegel segundo a edição: HEGEL, G. W. F. Werke in zwanzig Bänden: Theorie-Werkausgabe. Frankfurt am Main: Suhrkamp, 1970 (=TWA).

7 "Gott ist gestorben, Gott ist tot - dieses ist der fürchterlichste Gedanke, daß alles Ewige, alles Wahre nicht ist, die Negation selbst in Gott ist; der höchste Schmerz, das Gefühl der volkommenen Rettunglosigkeit, das Aufheben alles Höheren ist damit verbunden. Der Verlauf bleibt aber nicht hier stehen, sondern es tritt nun die Umkehrung ein; Gott nämlicht erhält sich in diesem Prozess, und dieser ist nur der Tod des Todes. Gott steht wieder auf zum Leben: es wendet sich somit zum Gegenteil"(TWA, 17, 290-291). 
a constituição da forma chamada absoluta. A forma absoluta consiste na ideia do próprio pensamento filosófico.

O pensamento filosófico desenvolve-se na forma da auto-reflexão, descobrindo, deste modo, a sua própria atividade (energeia). Para Hegel, tal como para Aristóteles e Plotino, a filosofia é essencialmente "pensamento do pensamento (noêseôs noêsis)" ${ }^{8}$ O horizonte da filosofia é, então, o pensamento de si mesmo, a autoconsciência do pensador. Mesmo se a religião cristã não parece basear-se na auto-reflexão, no entanto, no dogma da trindade, para escolher um exemplo preferido de Hegel, trata-se de fato de um sujeito absoluto referindo-se a si mesmo.

A estrutura da reflexão em Hegel, porém, não se deve confundir com Deus, se por "Deus" entendemos um espírito que transcende o mundo e que existe independente do nosso pensamento finito. Em Hegel, Deus - ou seja, o espírito absoluto - apenas designa a dimensão da reconciliação do espírito finito com a totalidade. $\mathrm{O}$ espírito absoluto nada mais é do que "a unidade da natureza divina e da natureza humana" (TWA, 17, 205). Esta unidade realiza-se pelo fato da atividade do pensamento determinar tudo aquilo que existe. Com efeito, Deus é a unidade ativa, criadora de sujeito e objeto, origem da disjunção. “Deus é atividade, ação livre, referindo-se a si própria, atividade que permanece em si; é a determinação fundamental no conceito ou em toda a representação do divino, i. e., de ser ele próprio a sua mediação" (TWA, 17,367). ${ }^{9}$

Quando determinamos algo como tal, pretendemos apreender um certo estado de coisas num horizonte conceitual. Este horizonte, ou seja, o espaço lógico, Hegel designa por "conceito". O conceito torna-se ideia absoluta uma vez que percebemos que não pode haver nada que fica totalmente indeterminado, dado que até o indeterminado é determinado como indeterminado. Nesse sentido, tudo aquilo que existe faz

8 Veja-se o meu artigo sobre GABRIEL, M. Hegel und Plotin. In: HEIDEMANN, D.; KRIJNEN, C. (Ed.). Hegel und die Geschichte der Philosophie. Darmstadt: Wissenschaftliche Buchgesellschaft, 2007; KONINCK, T.; PLANTY-BONJOUR, G. La question de Dieu selon Aristote et Hegel. Paris: Presses Universitaires de France, 1991.

9 "Gott ist tätigkeit, freie, sich auf sich selbst beziehende, bei sich bleibende tätigkeit; es idt die Grundbestimmung in dem Begriffe oder auch in aller Vorstellung Gottes, er selbst zu sein, als Vermittlung seiner mit sich“" (TWA, 17, 367).

Rev. Filos., Aurora, Curitiba, v. 23, n. 33, p. 525-537, jul./dez. 2011 
parte do conceito, que é a Verdade. A verdade abre-se ao nosso entendimento precisamente porque o nosso entendimento ocorre no seio da própria totalidade.

Ao contrário de Kant e de toda a tradição da epistemologia moderna, Hegel não acredita que o sujeito se opõe ao mundo, mas, sim, que a disjunção entre sujeito e objeto deve-se a uma separação interna da própria totalidade, fato esse que Hegel designa por "juízo (Urteil)". $\mathrm{Na}$ "etimologia" filosófica de Hölderlin e Hegel, a palavra alemã "Urteil" quer dizer "separação originária (ursprüngliche Teilung)" (TWA, 6, 303).

De fato, esta ideia radica na filosofia kantiana, uma vez que Kant define o pensamento humano como "julgar (urteilen)" ${ }^{10}$ Segundo a epistemologia kantiana, a única maneira de apreender o mundo realiza-se através do juízo que sujeita as coisas às formas da razão. Por isso, não conseguimos pensar algo que transcende as nossas formas racionais mesmo se houvesse algo transcendente, um mundus intelligibilis. Fora ou antes da separação de sujeito e objeto não podemos determinar nada. Por esta razão, as coisas são, num certo sentido, pensamentos e não coisas em si mesmas, como nos diz Kant. O mundo como mundo, i.e., todas as formas de organizar os elementos do mundo, de colocá-los em ordem, resulta do juízo. Contudo, a constituição do mundo apenas é possível no contexto de uma comunidade lingüística que Hegel qualifica como "espírito". ${ }^{11}$ Enquanto que Kant ainda pensa o sujeito constituinte numa forma solipsista e, certamente, não como comunidade, Hegel diz-nos que o espírito é “Eu que é Nós, e Nós que é Eu (Ich, das Wir, und Wir, das Ich ist)" (TWA, 3, 144).

Na metafísica hegeliana, porém, o absoluto não é nada mais do que um processo de manifestação. A natureza, a história, a arte e a religião são diferentes formas de expressão do absoluto, manifestações da

${ }^{10}$ Die Sache der Sinne ist, anzuschauen; die des Verstandes, zu denken. Denken aber ist Vorstellungen in einem Bewußtsein vereinigen. [...] Die Vereinigung der Vorstellungen in einem Bewußtsein ist das Urteil. Also ist Denken soviel, als Urteilen, oder Vorstellungen auf Urteile überhaupf beziehen. [...] Urteile, sofern sie bloß als die Bedingung der Vereinigung gegebener Vorstellungen in einem Bewußtsein betrachtet werden, sind Regeln. Diese Regeln, sofern sie die Vereinigung als notwending vorstellen, sind Regels a priori“ (Prolegomena, §§ 22-23).

11 Veja-se STEKELER-WEITHOFER, P. Philosophie des Selbstbewußtseins: Hegels System als Formanalyse von Wissen und Autonomie. Frankfurt am Main: Suhrkamp, 2005. 
estrutura do ser enquanto tal. "Ser" em Hegel significa: Manifestação, i. e., uma estrutura que Hegel designa por "realidade (Wirklichkeit)". O que se manifesta, manifesta-se a alguém, ou seja, "aparecer quer dizer aparecer um ao outro; este outro é a comunidade (Erscheinen ist Sein für Anderes; dies Andere ist die Gemeinde)" (TWA, 17, 278). Em última analise, Deus reduz-se à manifestação da totalidade na comunidade dos fiéis.

É essencial no conceito de religião verdadeira, i. e., daquela cujo conteúdo é o Espírito absoluto, que ela seja revelada e revelada por Deus. Com efeito, sendo dado que o saber, o princípio graças ao qual a substancia é espírito, é como forma infinita para ela mesma, sendo pura e simplesmente o Manifestar; o Espírito só o é na medida em que é para si, de tal modo que, na religião absoluto, o Espírito absoluto já não manifesta mais os seus momentos abstratos, mas manifesta-se a si próprio. ${ }^{12}$

Os fiéis não sabem que só celebram a manifestação da manifestação e não a manifestação de algo transcendente. $O$ fato de algo ser inteligível, i.e., compreensível, é uma manifestação da manifestação, i.e., o conceito. Deus não é, então, uma substancia que existe independentemente da comunidade, mas apenas uma representação da comunidade.

Essa concepção parece-se com a famosa tese de Feuerbach segundo a qual todos os Deuses apenas são projeções da consciência finita. Contudo, Hegel insiste que as nossas projeções de Deus são autoprojeções dele. Com efeito, deus é a projeção de si mesmo, ou seja, o sujeito absoluto. O sujeito absoluto constitui-se através da consciência humana que se autoposiciona.

Deus é apenas Deus na medida em que se conhece a si mesmo; o seu saber de si é além disso a consciência de si no homem e o saber que o homem tem de Deus, o qual progrido até ao saber de si do homem em Deus. ${ }^{13}$

12 Enc. §564: “ES liegt wesentlich im Begriffe der wahrhaften Religion, d.i derjenigen, deren Inhalt der absolute Geist ist, daß sie geoffenbart und zwar von Gott geoffenbart sei. Denn indem das Wissen, das Prinzip, wodurch die Substanz Geist ist, als die unendliche für sich seiende Form das Selbstbestimmende ist, ist es schlechthin Manifestieren; der Geist ist nur Geist, insofern er für den Geist ist, und in der absoluten Religion ist es der absoluto Geist, der nicht mehr abstrakte Momente siener, sondern sich selbst manifestiert."

${ }^{13}$ "Gott ist nur Gott, insofern er sich selber weiß; sein Sichwissen ist ferner sein Selbstbewußtsein im Menschen und das Wissen des Menschen von Gott, das fortgeht zum Sichwissen des Menschen in Gott." (Enc. §564, nota).

Rev. Filos., Aurora, Curitiba, v. 23, n. 33, p. 525-537, jul./dez. 2011 
A consciência finita compreende que faz parte de um contexto imanente. Enquanto que a epistemologia moderna depende da ideia de um sujeito solipsista excluído da totalidade das suas representações, Hegel integra a consciência, o pensamento no próprio Ser. Com efeito, o Ser pensa-se a si mesmo, estrutura essa que Hegel designa por "idéia absoluta". No caso do espírito absoluto isto quer dizer que ele se realiza na comunidade dos fiéis que Hegel identifica com o Espírito Santo:

Deus é consciência de si próprio, ele conhece-se a si mesmo numa consciência distinta que é em si a consciência de Deus, mas também para si, porque conhece a sua identidade com Deus, uma identidade que é, no entanto, mediada através da negação da finitude. - Este conceito constitui o conteúdo da religião. Deus é isto: que se diferencia de si mesmo, que é objeto de si, mas que nessa diferença é simplesmente idêntico a si, i.e., o Espírito. Esse conceito está agora realizado, a consciência conhece este conteúdo e nele ela conhece-se puramente entrelaçada; no conceito, que é o processo de Deus, ele próprio é momento. A consciência finita conhece Deus apenas na medida em que Deus se conhece a si próprio; assim, Deus é Espírito, e na verdade o Espírito d sua comunidade, i.e., daqueles que o veneram está é a religião realizada, o conceito tornado objetivo. Aqui se revela o que Deus é; ele já não é mais um para além, um desconhecido, porque manifestou ao homem aquilo que ele é e não simplesmente numa história exterior, mas na consciência. Por conseguinte, temos aqui a religião da manifestação de Deus, visto que Deus conhece-se num espírito finito. Deus é puramente revelado (TWA, 17, 186). ${ }^{14}$

Deus é o fato de o Ser se tronar inteligível no nosso pensamento do Ser. Deus manifesta-se na consciência finita. Mesmo se todas as

14 "Gott ist Selbstbewußtsein, er weiß sich in einem von ihm verschiedenen Bewußtsein, das an sich das Bewußtsein Gottes ist, aber auch für sich, indem es seine Identität mit Gott weiß, einde Identität, die aber vermittelt ist durch die Negation der Endlichkeit. Dieser Begriff macht den Inhalt der Religion aus. Gott ist dies: sic von sich sekbst zu unterscheiden, sich Gegenstand zu sein , aber in diesem Uterschiede schlechthin mit sich identisch zu sein - der Geist. Dieser Begriff ist nun realisiert, das Bewußtsein, weiß diesen Inhalt, und in diesem Inhalt weiß es sich schlechthin verflochten: in dem Begriff, der der Prozeß Gottes idt, ist es selbst Moment. Das endliche Bewußtsein weiß Gott nur insofern, als Gott sich in Ihm weiß; so ist Gott Geist, und zwar der Geist seiner Gemeinde, d.i. derer, die ihm verehren. Das ist die vollendete Religion, der sich objektiv gewordene Begriff. Hier ist es offenbar, was Gott ist; er ist nicht mehr ein Jenseits, ein Unbekanntes, denn er hat den Menschen kundgetan, was er ist, und nicht bloß in einer äußerlichen Geschichte, sondern im Bewußtsein. Wir haben also hier die Religion der Manifestation Gottes, indem Gott sich im endlichen Geiste. Weiß. Gott ist schlechthin offenbar" (TWA, 17, 186). 
religiões são manifestações de Deus. A religião cristã é distinta por ser uma religião de segunda ordem. Com efeito, manifesta que não há um conteúdo transcendente para manifestar, mas apenas a manifestação enquanto tal. Na forma da representação, esta estrutura exibe-se na esteira da morte de Cristo quando a cortina no templo é destruída. O conteúdo místico retira-se e os sacerdotes perdem o poder sobre os conteúdos não-humanos. Por outras palavras, Deus torna-se homem.

\section{Espírito da Comunidade}

Já no capítulo sobre a "Religião", na Fenomenologia do Espírito, Hegel critica a forma da representação porque divide a totalidade num mundo para além ("em si") e num mundo para aquém ("para nós").

Esta forma da representação constituí a determinação na qual o Espírito na sua comunidade se torna consciente de si. Esta forma não é ainda a consciência de si do espírito chegada ao seu conceito como conceito; a mediação ainda não está terminada. Há, assim, neste elo entre o ser e o pensar uma falta, a saber, que a natureza espiritual está ainda afetada por uma cisão irreconciliável entre um aqui e um para lá. O conteúdo é o verdadeiro, mas todos os seus momentos, sendo posicionados no elemento da representação, têm o caráter de não serem concebidos, mas de se manifestarem como lados completamente independentes que apenas se relacionam um com o outro exteriormente (TWA, 3, 555). ${ }^{15}$

Em outras palavras, a comunidade ainda não se apercebe do seu próprio fundamento que não transcende, mas que se encarna nas decisões desta ao aceitar um leque de tradições como fundamento ético

15 "Diese Form des Vorstellens macht die Bestimmtheit aus, in welcher der Geist in dieser seiner Gemeine seiner bewußt wird. Sie ist noch nicht das zu seinem Begriffe als Begriffe gediehene Selbstbewußtsein desselben; die Vermittlung ist noch unvollendet. Es ist also in dieser Verbindung des Seins und Denkens der Mangel vorhanden, da $\beta$ das geistige Wesen noch mit einer unversöhnten Entzweiung in ein Diesseits und Jenseits behaftet ist. Der Inhalt ist der wahre, aber alle seine Momente haben, in dem Elemente des Vorstellens gesetz, den Charaketr, nicht begriffen zu sein, sondern als vollkommen selbständige Seiten zu erscheinen, sie sich äußerlich aufeinander beziehen" (TWA, 3, 555).

Rev. Filos., Aurora, Curitiba, v. 23, n. 33, p. 525-537, jul./dez. 2011 
sobre o qual se baseia uma forma de vida. Ao deificar-se a comunidade religiosa, na realidade, reifica-se.

$\mathrm{Na}$ verdade, a comunidade não quer realizar a famosa visão de Pessoa na Tabacaria segundo a qual a comunidade (tal como o indivíduo) é tudo precisamente por não ser nada, ou seja, a comunidade reprime a contingência das suas decisões. Contudo, Hegel não apenas critica a religião mas sabe bem que as religiões atuam como mediadoras entre seres limitados (membros da comunidade) e a esfera geral (à qual Hegel designa por "universal") na qual os seres limitados determinam-se numa estrutura diferencial do conceito. Por isso, a filosofia da religião de Hegel distingue-se da crítica da religião do Iluminismo alemão e francês. Hegel aceita que a forma da religião representa um patamar necessário no processo da destruição da metafísica da substância. Esta última ainda acredita num Ser substancial que assegura tanto o desenvolvimento da humanidade como o indivíduo neste mundo que, na verdade, carecem de um sentido universal, determinado por Deus. A ideia de Deus enquanto garantia transcendente do sentido deste mundo tem que morrer antes que o espírito da comunidade possa aperceber disso.

A morte desta representação contem igualmente a morte da abstração do ser divino, que não é posto como ele próprio. Esta morte é o sentimento doloroso da consciência infeliz de que o próprio Deus está morto. Esta dura expressão é a expressão do saber de si mais íntimo, o retorno da consciência na profundidade da noite do $\mathrm{Eu}=\mathrm{Eu}$, que não se distingue e não sabe mais nada além disso. Este sentimento é, com efeito, a perda da substancia e da sua posição em face da consciência; mas é, ao mesmo tempo, a pura subjetividade da substancia ou a pura certeza de si própria que lhe faltava enquanto objeto, imediato ou puro ser. Este saber é assim a espiritualização através da qual a substancia se torna sujeito, pela qual a abstração e a sua falta de vitalidade são mortas, ela qual ela se torna efetivamente consciência simples e universal de si mesma. Deste modo, o Espírito é Espírito que se sabe a si mesmo; ele conhece-se; o que para ele é objeto é, na sua representação é o verdadeiro conteúdo absoluto; exprime, como dissemos, o próprio Espírito. Ele é, ao mesmo 
tempo, não apenas o conteúdo da consciência de si e não apenas o objeto para ela, mas é ainda Espírito real (TWA, 3, 571). ${ }^{16}$

Na religião absoluta o espírito encontra-se a si mesmo. Desta maneira, Hegel interpreta "o testemunho do espírito (Zeugnis des Geistes)" do qual São Paulo fala na Carta aos Romanos (Rom. 8, 16-17).

O testemunho do Espírito é, na sua forma mais elevada, a forma da filosofia, que se conhece como puro conceito como tal sem pressupormos para lá de ser a verdade explanada e que se explana, compreendendo-se no próprio desenvolvimento desta necessidade (TWA, 17, 198). ${ }^{17}$

O espírito manifesta-se sem manifestar algo determinado. $\mathrm{O}$ espírito torna-se, então, no sujeito absoluto que não tem nenhuma substância. Por outras palavras, o espírito absoluto designa a humanidade quando se questiona pelo fato de que há algo e não nada. O espírito absoluto pressupõe o desenvolvimento tanto do espírito subjetivo como do objetivo, o que significa que o espírito absoluto se realiza numa comunidade de seres humanos que se interrogam sobre as condições de possibilidade do mundo simbólico no qual residem.

16 "Der Tod dieser Vorstellung enthält also zugleich den Tod der Abstraktion des göttlichen Wesens, das nicht als Selbst gesetzt ist. Er ist das schmerzliche Gefühl des unglücklichen Bewußtseins, daß Gott selbst gestorben ist. Dieser harte Ausdruck ist der Ausdruck des innersten sich einfach Wissens, die Rückkehr des Bewußtseins in die Tiefe der Nach des Ich=Ich, die nichts außer ihrmehr unterscheidet und weiß. Dies Gefühl ist also in der tat der Verlust der Substanz und ihres Gegenübertretens gegen das Bewußtsein; aber zugleich ist es die reine Subjektivität der Substanz oder die reine Gewißheit seiner selbst, die ihr als dem Gegenstande oder dem Unmittelbaren oder dem reinen Wesen fehlte. Dies Wissen also ist die Begeistung, worduch die Substanz Subjetkt, ihre Abstraktion und Leblosigkeit gestorben, sie also wirklich und einfaches und allgemeines Selbstbewußtsein geworden ist. So ist also der Geist sich selbst wissender Geist; er weiß sich; das, was ihm Gegenstand ist, oder seine Vorstellung ist der wahre absolute Inhalt; er drückt, wie wir sahen, den Geist selbst aus. Er ist zugleich nicht nur Inhalt des Selbstbewußtseins und nicht nur für es Gegenstand, sondern er ist auch wirklicher Geist" (TWA, 3, 570-571).

17 "Das Zeugnis des Geistes in seiner höchsten Weise ist die Weise der Philosophie, da $\beta$ der Begriff rein als solcher ohne Voraussetzung aus sich die Wahrheit entwickelt und man entwickelnd erkennt und in und durch diese Entwicklung die Notwendignketi desselben einsieht" (TWA, 17, 198).

Rev. Filos., Aurora, Curitiba, v. 23, n. 33, p. 525-537, jul./dez. 2011 


\section{Referências}

HEGEL, G. W. F. Werke in zwanzig Bänden: Theorie-Werkausgabe. Frankfurt am Main: Shrkamp, 1970.

HEIDEGGER, M. Nietzsches Wort 'Gott ist tot'. In: HEIDEGGER, M. Holzwege. 6. Aufl. Frankfurt: Vittorio Klostermann, 1980.

HOULGATE, S. Hegel, Nietzsche and the criticism of metaphysics. Cambridge, UK: Cambridge University Press, 1986.

Recebido: 15/06/2011

Received: 06/15/2011

Aprovado: 19/07/2011

Approved: 07/19/2011 